Modalidades represivas contra los trabajadores chilenos en la Patagonia argentina: el caso de los obreros expulsados de Chubut

Gonzalo Pérez Álvarez - Mónica Gatica

páginas / año 12 - n 28 Enero-Abtil / ISSN 1851-992X/ 2020

http://revistapaginas.unr.edu.ar/index.php/RevPaginas

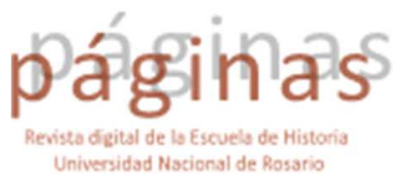

\title{
Modalidades represivas contra los trabajadores chilenos en la Patagonia argentina: el caso de los obreros expulsados de Chubut
}

\author{
Repressive methods against Chilean workers in Argentina's \\ Patagonia: the case of workers expelled from Chubut
}

\author{
Gonzalo Pérez Álvarez \\ Instituto de Investigaciones Históricas y Sociales; \\ Universidad Nacional de la Patagonia "San Juan Bosco"; \\ Consejo Nacional de Investigaciones Científicas y Técnicas (Argentina) \\ Mónica Gatica \\ Instituto de Investigaciones Históricas y Sociales; \\ Universidad Nacional de la Patagonia "San Juan Bosco"; \\ Consejo Nacional de Investigaciones Científicas y Técnicas (Argentina)
}

\begin{abstract}
Resumen
Al profundizar el conocimiento sobre el proceso de conformación de la clase obrera en Chubut y Patagonia, se destaca la fundamental presencia de los trabajadores de origen chileno. Ellos aportaron sus tradiciones de lucha y organización a la dinámica conformación de la clase obrera regional, en un contexto permanentemente interpelado por discursos y prácticas represivas, en aras de la supuesta consolidación de la "soberanía nacional".

Las y los obreros de origen chileno eran necesarios en una región con escasez de fuerza de trabajo, pero a la vez eran sindicados como una latente amenaza que enfrentaba la pretendida "argentinización" de la Patagonia. Esos obreros chilenos sufrieron un permanente control que en muchos casos desembocó en represión abierta. Trabajamos con la carpeta "Expulsados" del Archivo de Prontuarios Policiales, afincado desde el año 2016 en el Instituto de Investigaciones Históricas y Sociales de la Universidad Nacional de la Patagonia. A la fecha hemos dado con cinco prontuarios de obreros chilenos que fueron expulsados del país en los años '70 del siglo XX.
\end{abstract}

Palabras clave

Trabajadores Chilenos; Patagonia; Represión; Prontuarios; Archivo

\begin{abstract}
Deepening knowledge about the process of formation of the working class in Chubut and Patagonia, the fundamental presence of workers of Chilean origin stands. They contributed their traditions of struggle and organization to the dynamic conformation of the regional working class, in a context permanently challenged by repressive speeches and practices, for the supposed consolidation of "national sovereignty".

The workers of Chilean origin were necessary in a region with a shortage of labor force, but at the same time they were syndicated as a latent threat facing the alleged "argentinization" of Patagonia. These Chilean workers suffered permanent control that in many cases led to
\end{abstract}

Esta obra está sujeta a la Licencia Reconocimiento-NoComercial-CompartirIgual 4.0 Internacional de Creative Commons. http://creativecommons.org/licenses/by-nc-sa/4.0/

(cc) BY-NC-SA 


\section{Gonzalo Pérez Álvarez - Mónica Gatica}

open repression. We work with the "Expelled" folder of the Archive of Police Prosecutors, established since 2016 at the Institute of Historical and Social Research of the National University of Patagonia. To date we have found five records of Chilean workers who were expelled from the country in the 70's of the 20th century.

\section{Keywords}

Chilean Workers; Patagonia; Repression; Prosecutors; Archive

\section{Introducción}

En el marco de la investigación sobre las experiencias de la clase obrera en Chubut, siempre destacamos la fundamental presencia de los trabajadores de origen chileno (Gatica, 2013; Pérez Álvarez, 2015). Ellos aportaron sus tradiciones de lucha y organización a la dinámica conformación de la clase obrera regional, en un contexto permanentemente interpelado por discursos y prácticas represivas, en aras de la supuesta consolidación de la "soberanía nacional". Desde el Estado nacional argentino se pensó al territorio de Chubut como amenazado, extenso, poco poblado y tardíamente incorporado a la estatalidad (Pérez Álvarez, 2016; Gatica, 1998).

Las y los obreros de origen chileno eran necesarios en una región con escasez de fuerza de trabajo, pero a la vez eran sindicados como una latente amenaza, que ponía en riesgo la intención de "argentinizar" la Patagonia, tarea siempre demandada por los jerarcas militares (Villegas, 1969). Esos obreros chilenos sufrieron un permanente control, que en muchos casos desembocó en represión abierta.

Para este artículo nos centramos en el análisis de la carpeta "Expulsados" del Archivo de Prontuarios Policiales, afincado desde el año 2016 en el INSHIS de la UNP. Es un fondo documental con más de 60 mil prontuarios que recogen información sobre la vida de los sectores populares de todo Chubut. A la fecha hemos dado con cinco prontuarios de migrantes chilenos, todos de origen obrero, que fueron expulsados de Argentina. Avanzamos así, en el conocimiento acerca de las diversas modalidades represivas que sufrieron los trabajadores de nacionalidad chilena en Patagonia.

Compartimos con Águila la preocupación por poner en diálogo, y comprender las lógicas que han operado para el funcionamiento del aparato represivo, develando estrategias de disciplinamiento y control implementadas por el Estado ${ }^{1}$, indagando en los efectos que supuso sobre los sujetos afectados (2018: 68).

\footnotetext{
${ }^{1}$ La presencia del Estado nacional en los territorios patagónicos estuvo asociada a la presencia de policía, funcionarios de tierras, y justicia federal, con severas restricciones a los derechos políticos de sus habitantes. Aunque cumplían con los deberes como ciudadanos de la Nación -pagar impuestos, armarse en defensa de la patria- no podían participar en las elecciones nacionales de presidente y vice, legisladores nacionales (senadores y diputados), ni tener representación parlamentaria hasta 1957 (Ruffini, 2012). Sólo podían elegir al concejo municipal y al juez de paz si habitaban en pueblos de más de mil habitantes.

Aunque no podemos extendernos aquí, consideramos que la incorporación al Estado fue asociada al establecimiento y desempeño de las fuerzas armadas en el territorio, que en nuestra provincia supuso la creación de una Gobernación Militar en torno a Comodoro Rivadavia, la que muy
} 


\section{Modalidades represivas contra los trabajadores chilenos en la Patagonia argentina: el caso de los obreros expulsados de Chubut}

\section{Sobre cómo leer estos prontuarios}

Sabemos de la complejidad del trabajo de archivo y de los más que relevantes debates historiográficos planteados en torno a su utilización y a la manera en que deben ser problematizados y divulgados los datos que allí se encuentren. Esta dificultad adquiere un rasgo aún mayor cuando se trata, como en estos casos, de archivos sensibles, que nos hablan sobre sujetos que fueron victimizados por el Estado.

Seguimos aquí el artículo de Gatica (2011), que propone un recorrido necesario para el trabajo con estos archivos sensibles. Allí la autora analiza y describe los modos necesarios de abordar la información contenida en esos documentos y los debates en torno a cómo difundirla. Para ello es fundamental respetar a los sujetos involucrados, pero a la vez se debe resguardar nuestro compromiso con la necesidad de dar a conocer los procesos históricos que se desarrollaron. En esa perspectiva también nos han acercado reflexiones y aportes, en torno a los modos de analizar estos archivos, los trabajos de Nazar y Linares (2007) y de Sirimarco (2010), entre otros.

El abordaje de estos archivos complejos y sensibles, nos obligó a "aprender a escuchar" esas distintas formas de comunicar e interpelarnos que estaban contenidas en estas particulares fuentes. Así describía el Subcomandante Marcos la experiencia zapatista (o "neozapatista") en la selva Lacandona (Payeras \& Guillén, 2003) y la necesidad que tuvieron de no ocupar el aparente silencio con sus palabras, para que fuese posible aprehender lo que esos "otros" tenían para decir. Un proceso semejante buscamos realizar aquí con estos archivos, donde aparece centralmente la palabra del poder, pero también se filtra, entre las grietas de esa aparente voz omnímoda, la experiencia del dominado. El archivo nos da elementos para acercarnos a comprender su historia, su vida, entre esos fragmentos que la maquinaria estatal dejaba entrever. Podemos observar aspectos de su experiencia vital mediante el relato del archivo, a través de esa "historia contada" donde confluyen una serie de continuidades mediadas por la noción de "encadenamiento de una vida", como señalaba Paul Ricoeur (1999).

Son los "indicios" que nos permiten reconstruir esos recorridos que, a su vez, son parte de la historia de un colectivo social claramente definido: el de los obreros chilenos en la Patagonia argentina. Seguimos en esta mirada "indiciaria" a los señeros trabajos de Guinzburg $(1998,2013)$, quien nos develó caminos posibles

tempranamente controló y vigiló a agitadores, enemigos y potenciales usurpadores, "librando a Chubut de la plaga comunista" (Bohoslavsky, 2007: 7). El discurso nacionalista sostuvo que los miles de trabajadores chilenos que se instalaron en la región, eran potencialmente funcionales a quienes planificaban invasiones militares, mientras permitían el ingreso de hacienda robada, y mantenían un ardiente fervor patrio entre sus ciudadanos emigrados. Esta perspectiva entiende, entonces, que las prácticas represivas aquí reseñadas son parte de una política estatal sistemática, que trasciende a los gobiernos y hasta a los distintos regímenes políticos, aunque obviamente la praxis represiva se profundice durante las dictaduras. 


\section{Gonzalo Pérez Álvarez - Mónica Gatica}

para encontrar los rostros del pueblo entre los archivos del poder. Pero lo hacemos con las advertencias metodológicas, y políticas, que hiciera el Subcomandante Marcos (1996): "Quiero decir que este análisis o "rastreo" ("huellar al animal" decía el viejo Antonio) requiere de un marco de referencia. Algo con qué comparar o contrastar el indicio recabado".

Marcos señala que el enfoque de Guinzburg, “...'olvida’ el problema central: ¿cómo se "leen" los indicios?, ¿desde qué posición de clase? Si se salta de las anécdotas de cazadores a la ciencia de la historia, ¿cuáles son las "lecturas históricas" de los indicios recabados? ¿No hay que cuestionar el método de recolección de indicios? ¿No hay una posición de clase al elegir unos indicios sí y otros no? ¿No hay relación con una posición política al "leer" esos indicios? ¿No es, finalmente, ese criterio de selección de indicios y de lectura de ellos, un criterio de clase?".

Ese enfoque de clase es el que en este artículo recuperamos para leer estos archivos sensibles. Para ello: "Será necesario ir al cesto de la basura, desarrugar ese papel viejo y ajado que se llamó "La Ciencia de la Historia", el Materialismo Histórico" (Marcos, 1996). Rescatar el materialismo histórico en clave benjaminiana (Benjamin, 2007; Cerio, 2014), es parte de nuestra apuesta.

También hemos relevado el aporte de Lila Caimari (2017), con su importante libro que, cómo bien sostiene Pasolini (2017), "reubica el lugar del archivo, es decir, de los testimonios del pasado, para señalar sobre todo el aspecto primordial que juega en la investigación histórica" (243). Parte fundamental de los problemas que Caimari analiza y describe, se nos presentaron en nuestra investigación. La autora propone que "traducir el archivo a la escritura es, primero, renunciar" (Caimari, 2017: 11), comprendiendo que el intento de volcar todo lo que el archivo tenga para decir implica "...el peligro de la adicción, del ahogo, de la imposibilidad de abstracción" (13).

Caimari destaca esos riesgos, especificando su abordaje, además, en la particular complejidad de los archivos carcelarios y/o policiales, donde: "La voz de los dominados (los penados y penadas) aparecía mediada por filtros de peso ineludible, empezando por la violencia de la situación en la que esa voz emergía" (37). Por ello su libro permanentemente nos recuerda la necesidad de mantener nuestro estado de alerta acerca de los riesgos de trabajar con estos archivos, pero también de sus enormes potencialidades, ya que: "Transformar esos documentos en "fuentes", construir con ellos un archivo para la investigación, es una operación riesgosa y marcada por los problemas metodológicos que plantean los sesgos de las instituciones productoras. Pero este es, al fin y al cabo, un desafío común a muchas áreas de la historia" (73).

Por lo aquí desarrollado, y a fines de un ordenamiento lo más simplificado posible de la compleja trama construida en torno a cada uno de los "Expulsados", es que presentaremos los casos en forma particular, describiendo las características de sus kafkianos recorridos por el entramado de un sistema estatal represivo, injusto y, por momentos, aparentemente absurdo. Sabemos que esta forma de presentar los casos puede llevarnos a caer en esa "atracción del archivo" sobre la que nos alerta el 


\section{Modalidades represivas contra los trabajadores chilenos en la Patagonia argentina: el caso de los obreros expulsados de Chubut}

clásico aporte de Arlette Farge (1991), esa perspectiva que inocentemente confía en que el archivo pueda hablar por sí mismo.

No es esa nuestra mirada, como ya lo hemos sostenido. Pero en el caso de estos documentos, consideramos que la "banalidad del mal"2 que en ellos habita sólo puede ser sentida a través de una descripción densa (Geertz, 1983) de su contenido. Esa banalidad se verifica en muchos de estos procedimientos, donde el mismo Estado (o algunas de sus instituciones) parece verificar la injusticia de las operaciones efectuadas, pero al mismo tiempo sostiene, año tras año, la situación de la persona sancionada en aras de no incumplir las programaciones burocráticamente regladas.

La maquinaria estatal se muestra como desarticulada, imprecisa, hasta por momentos chapucera... Pero detrás de esa apariencia la represión y persecución de quiénes son considerados "diferentes" y/o "peligrosos", se mantiene homogénea y sin fisuras a lo largo de décadas, aun cuando los mismos actores estatales parecen detectar la injusticia intrínseca de sus prácticas.

Iremos retomando estas y otras preocupaciones a lo largo del artículo, para ser problematizadas en las reflexiones finales.

\section{Sobre el archivo}

En enero de 2016, el Instituto de Investigaciones Históricas y Sociales (INSHIS) de la Universidad Nacional de la Patagonia, sede Trelew, recibió de la Subsecretaría de Derechos Humanos de la Provincia de Chubut unos 60.000 prontuarios policiales que se encontraban en el Archivo Provincial de la Memoria (APM).

Estos documentos, producidos por la Jefatura de Policía de Chubut, contienen un acervo de información con gran potencialidad para la investigación. Se originan en delitos, contravenciones o trámites civiles de diversa índole (como certificados de buena conducta, solicitud de cédulas de identidad, registro de armas, pedido de licencias comerciales, etc.). ${ }^{3}$

La entrega a nuestro Instituto fue realizada en la caja de un camión volcador; los prontuarios estaban "presentados" en paquetes atados con hilo sisal o dentro de bolsas de consorcio. Tenían una gran suciedad y estaban desordenados, con las secciones mezcladas y sin lógica interna en su empaquetamiento. Por ello la tarea, hasta el presente, ha sido limpiar los prontuarios y ordenarlos, habilitándolos poco a poco para su consulta e investigación. Aún nos queda mucho por hacer, y los

\footnotetext{
${ }^{2}$ A la que hacía clásica referencia la reflexión de Hannah Arendt (1999).

${ }^{3}$ El espionaje, el control y la aplicación de prácticas represivas en el territorio de Chubut, es observable en el archivo en cuestión, con una extensa temporalidad que registra sus primeros antecedentes durante las décadas iniciales del siglo XX. La propuesta de avanzar en un análisis comparativo con el archivo DIPBA (que nos acerca una de las evaluaciones del artículo) se constituye en un objetivo relevante, ya que las temporalidades parecen ser semejantes. De todas maneras consideramos necesario profundizar el conocimiento del contenido disponible en diversos archivos sensibles, para poder establecer parámetros que permitan avanzar en los necesarios estudios comparativos.
} 


\section{Gonzalo Pérez Álvarez - Mónica Gatica}

trabajos presentados hasta el presente son aportes exploratorios, muestras de un mayor volumen de información que aún no hemos podido procesar por el escaso personal y presupuesto que tenemos a disposición.

Parte clave de la tarea fue identificar que los prontuarios se encuentran divididos en series menores ("secciones"), en torno al origen de su producción o al hecho que la institución productora del documento ha considerado el más relevante del prontuario en cuestión. Cada sección presenta algunas variaciones de procedimiento, consignando información de diferente índole. En principio, y según lo identificado hasta el presente, los prontuarios policiales de Chubut se organizan en torno a las siguientes secciones: AG (Archivo General); CI (Cédula de Identidad); LE (Leyes Especiales); SP (Seguridad Pública); RP (Repartición Policial); CC (Carta de Ciudadanía); RH (Robos y Hurtos); DE (Defraudaciones y Estafas); y la que en este artículo exploramos: E (Expulsados).

\section{Eleodoro Vasquez Vasquez}

Corresponde el número 230 de la sección "Expulsados".4 Inicia el prontuario una nota remitida desde Comodoro Rivadavia el 19 de septiembre de 2008, donde se informaba al "señor jefe de policía" 5 el fallecimiento de Eleodoro Vasquez Vasquez, indicando que tenía madre y padre ignorados, y que era nacido en La Unión, Chile, el 5 de agosto de 1931.

Cuenta con fotos de Eleodoro en 1978, en 1983 y otra sin fecha, pero claramente de al menos 10 años después a 1983 por el envejecimiento que se evidencia. En el prontuario sí se informa su filiación: es hijo de Salustiano Vasquez y de Micaela Vasquez, ambos chilenos, del pueblo de La Unión en Valdivia.

Eleodoro se presentó como soltero, de profesión cañista y declaraba no saber leer ni escribir. Ingresó al país en 1961, procedente de Coyhaique (en el prontuario dice "puerto de embarque", cuando en verdad llegó por tierra como casi la totalidad de la migración chilena), en el "Vapor"6 Empresa Giobbi (se trata de una antigua

\footnotetext{
${ }^{4}$ Recordando que hasta el momento sólo hemos encontrado cinco de estos casos. Es posible que muchos otros prontuarios hayan sido eliminados, especialmente cuando registraban, como algunos de los aquí consignados, casos evidentes de un procedimiento injusto que planteaba la posibilidad de reclamo por parte de las víctimas. Es posible que entre el conjunto de prontuarios que aún no hemos podido registrar, existan otros casos similares.

${ }^{5}$ El uso del entrecomillado, de aquí en adelante, referencia a citas textuales de diversas fojas o folios de cada uno de los prontuarios analizados. Por el formato de los mismos en muchos casos no es posible referenciar claramente al número de foja, tarea que además haría más dificultosa la redacción y lectura del artículo. La recurrencia a citar expresiones de uso habitual en los prontuarios, busca preservar formas discursivas propias del lenguaje hegemónico en el archivo trabajado.

${ }^{6}$ La referencia, en los prontuarios de Chubut, a la idea de que los migrantes llegados lo harían desde un "Puerto de Embarque" y en un "Vapor" es parte de la construcción de ese sentido común dominante (Gramsci, 1997) en Argentina, que invisibiliza u oculta la migración de origen latinoamericano (que en su enorme mayoría llega por tierra), para consolidar la imaginaria noción de que "los argentinos descienden de los barcos" (según la conocida frase de Octavio Paz). El proceso de imposición de una "atlantización" de la economía (Bandieri, 2005 y varios de los artículos compilados en Bandieri, 2011) y la consiguiente ruptura de los tradicionales vínculos regionales con
} 


\section{Modalidades represivas contra los trabajadores chilenos en la Patagonia argentina: el caso de los obreros expulsados de Chubut}

compañía de transporte terrestre). Su apodo era "Lolo" y tenía un mes de residencia en el país al momento de realizar el prontuario. El policía describió su aspecto como "humilde" y detalla sus principales datos corporales.

El prontuario nos permite conocer su recorrido laboral y sus diversos domicilios. Eleodoro siempre estuvo vinculado a la actividad petrolera, trabajando de manera inestable en distintas compañías de la cuenca del Golfo San Jorge, entre el sureste de Chubut y el norte santacruceño. En 1961 vivió en Comodoro Rivadavia, ese mismo año se trasladó a Cerro Dragón (yacimiento petrolero cercano a la localidad chubutense de Sarmiento), luego a Cañadón Seco (en la provincia de Santa Cruz) desde 1962. En 1968 se mudó a Pico Truncado y en 1978, última fecha registrada, volvía a ser ubicado en Comodoro Rivadavia.

Su trayectoria laboral termina de evidenciar ese recorrido: en 1961 fue jornalero para la Compañía Pérez Companc hasta 1962, allí pasó a trabajar en la Empresa Tres Estrellas, de Cañadón Seco. En 1964 se desempeñó en Artegan, hasta 1973. Desde 1974 trabajó en la Empresa Tehuelche, en Pico Truncado, y en 1977 en la Empresa Williams, ubicada en Comodoro Rivadavia. Su último registro laboral finalizó el 20 de septiembre de 1978, nuevamente en la Empresa Tehuelche de Pico Truncado. Eleodoro no tenía parientes declarados y citaba como personas "con quiénes se acompaña habitualmente" a dos compatriotas chilenos, que eran un matrimonio amigo.

El primer trámite registrado es del 20 de septiembre de 1978, cuando Eleodoro se presentó ante la policía de Chubut solicitando una nueva cédula de identidad, ya que había perdido su identificación (contaba con radicación definitiva en el país por Decreto 49/64; o sea, hacía ya 14 años).

Sin embargo, sin mayores novedades, el prontuariante informa que "se devolvió el trámite por estar expulsado", con fecha $3 / 7 / 84^{7}$, en manuscrito. Dos años después la Dirección Nacional de Migraciones informaba que "no se han ubicado antecedentes relacionados con la expulsión del mismo"8, también en manuscrito, con fecha $27 / 8 / 86$.

Se incorpora al prontuario el certificado de nacimiento y luego figura su declaración solicitando copia de la cédula de identidad perdida. La policía de Santa Cruz respondía coincidiendo con el pedido de Eleodoro, e informando que esa persona estaba radicada definitivamente en el país desde 1964.

\footnotetext{
Chile, también se realizaba a través de esos procesos de construcción de imaginarios y de ocultamiento de realidades.

${ }^{7}$ Los prontuarios no siguen un recorrido estrictamente cronológico, por lo cual la narración puede ser, por momentos, difícil de seguir. Optamos por describir el documento tal cómo fue elaborado por la organización productora, porque en su misma complejidad elabora esa idea de un laberinto burocrático kafkiano, donde lo que aparece como "sin razón" es el oscuro muro, que debe haber parecido prácticamente impenetrable para la víctima, de un Estado que articula su aparato represivo entre todas sus instituciones.

${ }^{8}$ En todos los casos las citas son textuales tal como constan en los prontuarios, aun cuando existan errores de redacción o tipeo.
} 


\section{Gonzalo Pérez Álvarez - Mónica Gatica}

El 9 de octubre de 1978 se informó que la cédula estaba en condiciones de ser entregada a Eleodoro. Sin embargo a continuación figura un breve escrito, en mimeógrafo, que cita: "Para antecedentes de la EXPULSIÓN de nuestro país del causante, ver nota n⿳ 45/79 URCR del 16/3/1979 de la Unidad Regional de Comodoro Rivadavia...".

El laberinto represivo empezaba a encerrar a Eleodoro. Esa nota, dirigida al sub jefe de la policía, citaba un listado de "residentes ilegales en el país", creando el "archivo de expulsados". Esos sujetos habrían sido "detenidos en operaciones conjuntas, con efectivos del Ejército y Policía Federal, y que, dada la intervención a la Delegación Patagonia de la Dirección Nacional de Migraciones, fueron expulsados a su país de origen (CHILE)."

Son 65 personas, que enumeramos aquí para que sus nombres sean recuperados para la historia9; quienes aquí aparecen en cursiva fueron marcados en rojo en el documento de origen sin mayores datos de la razón de dicho señalamiento: Chavez Godoy, Diógenes; Chiguay Cárdenas, Luis Humberto; Uribe Haro, Manuel Jesús; Arteaga Torres, Felipe Segundo; Huenchuguala Lorca, José Dalmiro; Naudan Ruiz, José Ernesto; Peralta Peralta, Bernabé; Cárdenas Godoy, Manuel; Mansilla Mansilla, Pedro Eludio; Marquez Villarruel, José Arturo; Cárcamo Torres, Alfonso; Almonacid Miranda, Raúl; Segura Flores, José Mercedes; Almonacid Gallardo, Pedro José; Ojeda Huenul, Carlos David; Tureuna Tureo, Celedonio; Toledo Navarro, José Armando; García Trigo, Manuel Segundo; Ainol Aguilar, José Olegario; Barría Rutte, Alfredo; Agüero Hernández, Wenceslao; Renin Renin, José Neptalí; Cárdenas Peso, Paulo Segundo; Barrera Alvarado, Juan Roberto; Chicoy Velázquez, Belarmino; Sánchez Gallardo, Alfonso; Aguilar Cárdenas, Gregorio; Reyes Contreras, Estela del Carmen; Haro Santana, Erme Arcalio; Nahuelquir Carrera, Pedro José; Alvarez Ojeda, Jorge; Madrid Gonzalez, Washington Luis; Vasquez Fica, Erica Adelaida; Millanco Navarro, Ramón; Millán Alvarado, Máximo; Rodriguez Robledo, Carlos Guillermo; Torres Alvarado, Juan Antonio; Aguilar Aguilar, Efraín Segundo; Vasquez Fica, Carlinda Perfina; Silva Ovando, Hegio; Gavilán Zuñiga, Manuel Hipólito; Hernández Mansilla, Carlos Alcides; Oyarzo Villegas, José (luego figuran cinco nombres tachados); Frías Gallardo, Antonio Segundo; Jara Fuentes, Carlos; Figueroa Castro, Luis; Sanchez Cienfuegos, Juan Bautista; Haro Ojeda, Manuel Jesús; Hernández Godoy, Manuel Moisés; Haro Contreras, Zacarías; Balboa Alfaro, Pedro; Torres Torres, Valdovino; Saldivia Aravena, Patricio Moisés; Cardenas Cardenas, Prudencio; Peralta Espejo, Raúl Nelson; Soto Guzmán, Juan; Mendez Nevenes, Jaime Belarmino; Igor Soto, Antonio Patricio; Vasques Vasques, Eleodoro; Arismendi Arismendi, Celedonio; Vera Vera, Reinaldo Amado; Ruiz Navarro, Luis Alberto; Copto Caico, Olegario; Rivas Cayuqueo, Héctor Daniel; Mansilla Pérez, José Miguel.

Debajo de los nombres figura esta inscripción: "Nota: los tachados es porque estaban repetidos". Se destacan nombres relacionados con estratos populares y rurales del

\footnotetext{
${ }^{9}$ A la vez hemos comenzado tareas de consulta en el Archivo Histórico de Chile, rastreando sus historias en el país vecino. Hasta el momento no hemos encontrado nuevos registros sobre sus historias de vida.
} 


\section{Modalidades represivas contra los trabajadores chilenos en la Patagonia argentina: el caso de los obreros expulsados de Chubut}

Chile de entonces, además de evidenciarse un componente claramente generizado en los blancos de la represión (sólo 3 de las 65 personas expulsadas eran mujeres). Luego de esa nota, en el prontuario se incorporó una ficha realizada en Pico Truncado por la policía de Santa Cruz, donde se consignaba que Eleodoro había sido expulsado del país. El término "Expulsado" fue inscripto en rojo, manuscrito, y con signos de admiración.

En noviembre de 1983 el comisario inspector Pedro Gutiérrez, jefe del departamento judicial de la policía de Chubut, le remitió una nota al jefe de la Unidad Regional de policía de Comodoro Rivadavia (URCR). Allí le requería información sobre las razones por las cuáles Eleodoro fue expulsado, ya que poseía documento argentino y se encontraba radicado legalmente desde 1964. A la vez le solicitaba datos sobre el tiempo que Eleodoro estuvo fuera del país: recordemos que ya habían pasado más de 4 años desde su expulsión.

En radiotelegrama emitido por la URCR al departamento judicial, se informaba que Eleodoro fue expulsado junto a otros residentes ilegales durante el año 1979. En octubre del '84, la dirección nacional de migraciones (DNM) de la delegación Comodoro Rivadavia (CR) destacaba que en sus registros no existían antecedentes sobre la expulsión de Eleodoro.

En noviembre de 1985 el departamento judicial elevó al asesor letrado de la jefatura de policía el pedido de que se le informe el "temperamento a adoptar con respecto a la expedición de dicho documento". Se refería así al inicial pedido de cédula de identidad elevada por Eleodoro, ya que la jefatura de Comodoro Rivadavia, y la DNM les notificó que no registraban antecedentes de su expulsión.

En febrero de 1986 se emitió una nota dirigida al delegado de la dirección de migraciones, solicitándole se sirviese requerir informes sobre la situación de Eleodoro. Se exigía allí pronto despacho, y estaba firmada por el departamento judicial de la policía de Chubut. Consta a continuación un nuevo pedido de Eleodoro, fechado en noviembre de 1985, solicitando su nueva cédula de identidad y remitiéndose a lo informado por migraciones sobre la ausencia de antecedentes y causas para su expulsión.

El 13 de marzo de 1986 le remitieron a Eleodoro todos los papeles presentados por él, en nota enviada por la policía de Chubut. Se le informaba que, como aún la DNM no se había expedido, aún no le podían entregar el documento. Sin embargo, en un laberinto difícil de seguir, el 2 de abril de 1986 la DNM volvía a informar que ese organismo no registraba antecedentes sobre su expulsión, en nota emitida desde el ministerio del interior.

Finalmente el laberinto pareció abrirse: el 11 de julio de 1986 el departamento judicial le ordenó al jefe de la URCR que citase a Eleodoro para entregarle la cédula de identidad provincial. Pero aún faltaba otro recodo; el 4 de agosto de 1986 Eleodoro volvió a solicitar la cédula de identidad, presentando otra vez todos los documentos que se le reclamaban a tal efecto. El 28 de agosto, Eleodoro recibió su anhelada cédula de identidad, tras casi siete años y medio desde su aprehensión y expulsión. 


\section{Gonzalo Pérez Álvarez - Mónica Gatica}

\section{José Alfredo Barría Ruti}

Su expediente está numerado como el 59 de la sección "Expulsados". José Alfredo se definía como agricultor y jornalero, nacido en 1920 en el pueblo de Maullín, provincia de Llanquihue, Chile. En un sobre pegado a la tapa del prontuario, se encuentra una nota fechada el 7 de agosto de 1951, donde se le hacía entrega de su documento de identidad argentino, aunque en el acto el mismo era retenido porque José no se encontraba en su domicilio. Además, en ese sobre se encuentran sus documentos chilenos.

Llegó a la provincia de Chubut en el "vapor" Limoi (también era una empresa de transporte terrestre) en septiembre de 1947 desde Aysén, y los policías detallaron sus características físicas en el prontuario. Evaluaron su aspecto social como "regular", su moralidad como "buena" y su concepto como "bueno". Su seña particular era utilizar anteojos ahumados, por tener un ojo lastimado.

Tuvo diversos domicilios en Chile hasta 1947, cuando migró hacia Comodoro Rivadavia. Allí vivió seis meses, del ‘47 al ‘48, y luego residió en Las Chapas y Trelew, por sus trabajos en el Dique Florentino Ameghino10, desde 1948. En 1947 fue peón en la empresa Conte Grande, en Comodoro Rivadavia, y en el '50 ingresó a la empresa Wast y Freyt, hasta 1955. Luego se desempeñó como peón en hornos de Faisca, hasta 1958.

Sólo informaba como parientes a un primo y un hermano, ambos en Maullín, y como conocido indicó a un patrón suyo, Juan Clever, de Trelew. Declaró que siempre había trabajado como peón y que no poseía ideología social.

Al igual que Eleodoro su prontuario se inició por su solicitud de cédula de identidad. Pero José Alfredo sí tuvo algunos procesos policiales vinculados a delitos: el 7 de abril de 1958 fue acusado por hurto y defraudación en el juzgado nacional de primera instancia de Comodoro Rivadavia. Y el 8 de febrero de 1961 tuvo una infracción policial por ebriedad, por la cual fue detenido durante un día.

Recibió su cédula de identidad en la comisaría de Dolavon durante el año 1951, mientras se encontraba trabajando en las obras del Dique Ameghino. La policía del Territorio le solicitó al encargado de la policía que "se sirva disponer el levantamiento de una amplia información sumaria mediante testimonio de dos o más personas caracterizadas del lugar que conozcan al recurrente con antelación al 8 de julio de 1949 (decreto número 24666/49)".

José propuso como testigos a Moisés Hernández, capataz de la usina del km 5 de Comodoro Rivadavia, y a Menéndez, dueño del hotel “Diana”, quienes, según él, lo conocían desde su ingreso al país. En seccional Comodoro Rivadavia, Menéndez, de 46 años, español, declaró que no conocía a José Barría, ni por el nombre ni por la

\footnotetext{
10 Que fuera inaugurado en 1963, con el objetivo de controlar las crecidas del Río Chubut y asegurar la provisión regular de agua al noreste de Chubut (pueblos y ciudades de 28 de Julio, Dolavon, Gaiman, Trelew, Rawson y Puerto Madryn).
} 


\section{Modalidades represivas contra los trabajadores chilenos en la Patagonia argentina: el caso de los obreros expulsados de Chubut}

fotografía y que por lo tanto nada podía informar, aclarando que podría ser alguna persona que hubiese conocido de vista y de la que ahora no hacía memoria.

Además Moisés Hernández aparentemente había regresado a Chile y no se lo podía encontrar. Era evidente la soledad de José, y el hecho de que sólo podía indicar como referencias a sus pasados patrones o a quién lo había alojado temporalmente en un hotel.

En el Dique Florentino Ameghino en 1951, la policía convocó a Remigio Álvarez, chileno, de 22 años, con 5 de residencia en Argentina, y a Miguel Ángel Paz. Remigio declaró que conocía a José hacía diez años, y que le constaba su origen, su religión católica, su conducta, concepto y moralidad buena, "tratándose de una persona contraída al trabajo y sin vicios".

Paz era argentino, de 58 años, jornalero. Relató que conocía a José desde cuatro años atrás, cuando llegó a Comodoro Rivadavia desde Chile, declarando exactamente lo mismo que Remigio. Vemos que cuando José recurrió a sus compañeros de trabajo la respuesta fue otra. Poco a poco se construían referencias comunes y alguna forma, aunque más no fuese muy embrionaria, de un colectivo laboral. Gracias a ello José consiguió su cédula de identidad.

En 1958 se lo identificó, ya que había sido acusado de hurto por Benito Clemente y por defraudación contra Macario Barrera, en la seccional segunda de Comodoro Rivadavia. El 26 de marzo se lo procedió a detener por estas acusaciones y se le instruyó sumario. Lo acusaba su patrón, indicando que le había robado una batería para vendérsela a Barrera en 100 pesos. El acusado reconoció el hecho, y fue encarcelado.

Se le realizó una nueva ficha en 1961, donde volvió a ampliar datos laborales. Allí informó que hasta 1947 trabajó como agricultor en Chile, y en 1947 como cortador de ladrillos en la Quinta de López, ubicada en el barrio General Mosconi de Comodoro Rivadavia.

Casi cerrando el expediente se integró una nota, del 26 de enero de 1979, elevada al jefe del departamento judicial por parte de la comisaría de Gaiman, adjuntando prontuarios completos de los siguientes ciudadanos chilenos: Juan Segundo Yambil Martinez (número 55 E), Leopoldo Mera Salazar, José Alfredo Barría Ruti, José Abraham Macareño Navarro, Pablo Segundo Pezo Cárdenas (todos incorporados al radiograma 26/78), Ramón Sánchez Benavidez (radiograma 9/79), Manuel Reyes Rojas (radiograma 11/79 y 16/79), Mario Ignacio Barría (radiograma 23/79), José Flavio Alvarado (radiograma 36/79) y José Rigos Alvarado Herrera.

Finalmente, y ya en ese marco de la detención para ser expulsado, José completaba una nueva planilla prontuarial, donde otra vez ampliaba la información sobre su desempeño laboral: desde 1948 hasta 1949 trabajó de peón en Santa Cruz, del '49 al '50 en el Dique Ameghino, en 1950 fue ladrillero, en 1952 y 1953 fue peón en Agua y Energía de Gaiman y Dolavon, desde 1953 a 1959 fue peón en Kank y Costilla, en Comodoro Rivadavia. En 1959 pasó a ser jornalero en distintos lugares de Santa Cruz, y en 1972 volvió a su oficio de ladrillero con Ansel Roberts, en Gaiman. La ficha es del 28 de enero de 1978, por motivos de "verificación de documentación", 


\section{Gonzalo Pérez Álvarez - Mónica Gatica}

ordenada por el jefe de área 536; o sea por orden directa de Carlos Alberto Barbot ${ }^{11}$. A continuación se informaba que José fue Expulsado, remitiendo a la nota 45/79 de la URCR. La orden de su deportación es fechada el 15 de febrero de 1978, efectivizándose el 18 de febrero de 1978.

\section{Manuel Antonio Reynahuel}

El primer dato a consignar es la diferencia en la escritura del apellido, ya que en la tapa del prontuario figura con "Y", y en la planilla con "I", o sea Reinahuel. El error en la tipografía tiene relevancia, ya que el apellido es el único, de los aquí registrados, de origen claramente mapuche. El expediente es el 123 de la serie "Expulsados" y la carátula no tiene fecha.

Manuel nació el 20 de junio de 1923 en Meullín, provincia de Chiloé. Casado, de profesión jornalero, con conocimientos de lectura y escritura (asistió hasta cuarto grado). Llegó a Argentina el 8 de octubre de 1952, "embarcando" en Puerto Montt en el "vapor" Trinidad. Su aspecto social fue calificado como "humilde", y su "concepto, conducta y moralidad", como "bueno".

Su primer domicilio en el país fue en Comodoro Rivadavia, donde vivió hasta 1967. Tenía vínculo con sus hermanos y madre en Chile, su esposa en Barrio La Floresta (de Comodoro Rivadavia) y sus tres hijas, en Barrio Don Bosco de la misma ciudad. En lo laboral siempre se desempeñó como jornalero. Trabajó en "Balcón y compañía", luego en "Compañía Americana Cerro Dragón », en 1960 pasó a "Loglan Americana", en 1962 se desempeñó en la "Compañía Prandi" (de Pico Truncado), y desde 1967 volvió a la compañía Balcón, de Comodoro Rivadavia.

La primera realización de prontuario fue por averiguación de antecedentes, el 24 de junio de 1967; allí también le realizaron su ficha. En 1978 se produjo una nueva actuación, originada en Gaiman, donde en el radiotelegrama se solicitaba información acerca de si a Manuel se le había otorgado una cédula de identidad por parte de la ex Gobernación Militar de Comodoro Rivadavia'2 ${ }^{12}$ ya que el prontuariado requería un duplicado de la misma.

Una semana después, el 24 de noviembre, desde Rawson respondieron que no había constancia de que Manuel fuese poseedor de esa cédula de identidad. El 26 de enero de 1979, en Puerto Madryn, el jefe de prefectura solicitó constatar si Manuel era poseedor de la citada cédula de identidad, remitiendo ese pedido de informes a la policía judicial de Chubut.

\footnotetext{
${ }^{11}$ Sobre la funesta figura de Carlos Alberto Barbot, ex jefe represivo del área 536 durante la dictadura militar e interventor de la Policía de Chubut, ver http://www.diariojornada.com.ar/35233/Sociedad/Barbot.

12 Ver Barros \& Carrizo, 2012: "Los territorios nacionales de Chubut y de Santa Cruz tuvieron una particularidad que los hace únicos en la experiencia argentina referida a la provincialización. Estos dos espacios fueron marcados por la existencia de la Gobernación Militar de Comodoro Rivadavia entre 1944 y 1955. Es decir, la singularidad estriba en que la organización de un sistema político provincial, a diferencia de otros espacios, no se instaló solamente a partir de un Territorio Nacional sino de una Gobernación Militar" (p. 2).
} 


\section{Modalidades represivas contra los trabajadores chilenos en la Patagonia argentina: el caso de los obreros expulsados de Chubut}

A continuación se incorporó al prontuario una nota previa, fechada el 19 de enero de 1979, en Gaiman, donde el jefe de esa comisaría consignaba que fueron detenidos "por carecer de documentación personal y justificación legal en el país siguientes ciudadanos chilenos: Mario Ignacio Barría, soltero, jornalero, alfabeto, nacido 12-950 en Punta Arenas, provincia, Magallanes-Chile, hijo Luis y Carmen Lizama, indocumentado, ddo. Chacra Zona La Angostura y Manuel Antonio Reynahuel, casado, jornalero, alfabeto, nacido 20-6-23 en Meullín, pcia. Chiloé, Chile, hijo NN y Emilia Reynahuel, indocumentado, ddo. Chacra Bryn Gwyn, estimaré medidas a adoptarse."

Sin que mediasen otras novedades, en el prontuario aparece a continuación otro radiograma fechado el 7 de junio de 1981, donde nuevamente el comisario de Gaiman solicitaba se le informase si Manuel era el titular de la cédula de identidad remitida previamente. Destacamos que ya habían pasado dos años y medio del trámite anterior y que para el momento de realización de estos angustiantes procedimientos Manuel ya registraba casi 28 años de residencia en Argentina.

Dos días después se emitió un radiograma al jefe de la URCR, solicitándole nuevamente la información sobre Manuel. El 10 de junio, en Comodoro se contestó ese requerimiento, consignando que "el causante fue poseedor de C.I. nro...13, expedida el 24-7-53, con fecha 7-2-56, se le otorgó documento mencionado en su radio, solo efecto acreditar identidad person NOMBRADO ingreso año 1952 por término seis meses".

El 12 de junio de 1981 se emitió un nuevo radiograma, dirigido desde Rawson a la comisaría de Gaiman, donde se consignó que Manuel sí tuvo cédula de identidad. El Estado parece reconocer el error de su expulsión, ya que Manuel era poseedor de una cédula argentina, pero no se ubica en el expediente ninguna actuación administrativa posterior, ni siquiera la entrega de la ansiada copia de la cédula, de un nuevo documento de identidad o, al menos, la revisión del procedimiento de expulsión.

\section{José Domingo Antil Alchao}

Su prontuario es el 468 "E"14, y no consta en la carátula fecha de inicio. En el sobre adjunto se encuentran las fichas dactiloscópicas, y la documental consigna que José Domingo era hijo de Andrés Antil y de Celinda Alchao, nacido en el pueblo de Pitrolquén, Provincia de Cautín, Chile, el 10 de enero de 1925. Era soltero, de profesión albañil y solamente sabía firmar.

La ficha que figura en primer lugar fue confeccionada el 2 de octubre de 1981, y la causa era debida a considerarlo un "residente ilegal". Se informa que el prontuariado fue puesto a disposición de la DNM: pocos días después, el 8 de octubre de 1981, José Domingo fue expulsado de Argentina. En el prontuario se observan 10 fichas

\footnotetext{
13 Evitamos citar los números de cédulas de identidad y de DNI nombrados en los prontuarios.

14 Número que brinda un dato sobre la enorme cantidad de "Expulsados" desde la provincia de Chubut.
} 


\section{Gonzalo Pérez Álvarez - Mónica Gatica}

dactiloscópicas, pero sólo la aludida tiene fecha, mientras que en las otras 9 se consignaban distintos domicilios en Comodoro Rivadavia o parajes cercanos.

José Domingo tenía una historia complicada, con diversas acusaciones por delitos graves. Son once actuaciones, entre denuncias, procesos y arrestos, entre el 5 de febrero de 1947 y el 5 de marzo de 1951, por desorden, ebriedad e infracción a la "resolución gubernamental 960/48"15. En todos los casos estos hechos sucedieron en territorios de YPF cercanos a Comodoro Rivadavia, interviniendo el Juez de Paz y debiendo pagar multas. El 23 de junio de 1952 José Domingo registró un antecedente de hurto, quedando en libertad bajo caución juratoria el 25 de julio de 1952. Hasta fines de junio de 1956, registró cinco nuevas detenciones con intervención del juez de paz, por ebriedad y desorden, abonando las correspondientes multas.

El 30 de octubre de 1958 se consignó un "supuesto estupro", siempre en Comodoro Rivadavia, quedando en libertad por orden del juez de instrucción el 3 de noviembre de ese mismo año. El 30 de abril de 1963, José Domingo fue nuevamente detenido por "lesiones leves". El Juez Letrado lo dejó en libertad bajo caución juratoria el 10 de mayo de ese año, siendo "condenado a sufrir la pena de ocho meses de prisión en suspenso, con costas, como autor responsable del delito de Lesiones Leves".

Luego se incorpora documental producida en la Comisaría del Barrio Oeste, en relación al robo del que fuera acusado en 1952. Consta allí un memo del Ministerio de Comunicaciones, siendo una copia carbónica manuscrita con el siguiente texto: "Subcomisario Barrio Oeste nro.111 comunico S.S. ayer denunció Andrés Herrera fue víctima robo un mil pesos moneda nacional acusando a Domingo Antil de quien se procura detención instruyo sumario - Barrenechea subcomisario, Barbolla secretario".

En la planilla de datos para el prontuario, que fue agregado con fecha 25 de junio de 1952, se detalla que José Domingo ingresó a Argentina en 1944, partiendo desde Aysén y llegando por vía terrestre. Refiere que no tiene instrucción, con concepto, conducta y moralidad "bueno" y de aspecto social "humilde". El motivo de la identificación se debió a una acusación de hurto; allí José presentó como documento un "certificado consular" expedido en Comodoro Rivadavia. Luego consta la orden de libertad concedida bajo caución juratoria.

Con fecha 20 de marzo de 1953, el juez nacional Ernesto Cano se dirigió al jefe de policía, notificando su incompetencia en la causa No.873, folio 736, instruida contra José Domingo Antil (prontuario No.7860 R.H). ${ }^{16}$ Se incorporó allí una nueva planilla de datos, que también remitía al prontuario de "Robos y Hurtos", con fecha 31 de diciembre de 1956, ocasión en la que José Domingo fue detenido por ebriedad. La

\footnotetext{
15 Según nuestros registros se trataría de una resolución interna de la Gobernación Militar de Comodoro Rivadavia, que permitía la detención temporaria de los extranjeros sin radicación definitiva.

${ }^{16}$ Aquí vemos que José tenía un prontuario en otra sección, la de R.H. ("Robos y Hurtos"). Se observa cómo la policía de Chubut adscribía cada individuo a una sección, de acuerdo a sus criterios. Pareciera, en este caso, que se considera más grave el hecho de haber sido "Expulsado" (y por ello se lo consigna en esa sección), que la previa característica de haber estado implicado en un delito.
} 


\section{Modalidades represivas contra los trabajadores chilenos en la Patagonia argentina: el caso de los obreros expulsados de Chubut}

información consignada es semejante, pero detalla que tenía una hermana en Comodoro Rivadavia y una concubina de nacionalidad argentina con quién compartía domicilio en Urquiza 120, junto a sus dos hijos.

Aquí, además, se detalla su trayectoria laboral: agricultor en Chile; peón en Diadema Argentina, kilómetro 27, entre 1944 y 1946; peón en la sección montaje de torres en YPF hasta 1952; peón en Empresa Nacionalizada de la Planta de Cinc en kilómetro 8 de Comodoro Rivadavia. Su ideología social fue consignada como "Ninguna".

Con fecha 13 de agosto de 1957, desde la Jefatura de Policía se comunicó al jefe de la Comisaría Seccional Segunda, que se había presentado Don Vicente Linares "formulando en forma verbal una queja contra N. Antil que vive al parecer en concubinato con Rosa Linares, a quién haría objeto de malos tratos para que tome intervención". Desde dicha dependencia citaron a Linares, quien en su declaración sostuvo: "al enterarse por medio de las noticias de la prensa y radio local que el Señor Subjefe de Policía en la Provincia se encontraba en esta ciudad y como eran sus deseos conversar con él personalmente y por cuyo motivo se dirigió hasta la Inspección de Policía "Comodoro Rivadavia" donde solicitó una audiencia y lograda la misma y una vez en presencia de dicho señor le hizo un comentario de una incidencia habida en su domicilio. No puede precisar la fecha pero dice que su hija Rosa y su concubino Antil se habían separado; y que encontrándose ella en su domicilio fue objeto de amenazas y la convenció para volver a vivir juntos".

Linares afirmó que él no fue molestado por Antil y que su hija lo visitaba periódicamente, pero que le ha manifestado que "le daba mala vida y como consecuencia de ello se producían entre ambos reyertas que nunca pasaron a mayores. Que en una oportunidad, no recordando fecha supo por boca de su propia hija que su concubino le había pegado y al parecer lesionado, habiendo tomado intervención la Comisaría". Es interesante que Linares pidió la audiencia para saber qué destino tuvo una denuncia semejante, que había enviado a Rawson hace algo más de dos años.

El 13 de septiembre compareció, después de haber sido citada reiteradamente, Rosa Linares. Ella declaró que hacía tres años vivía con Antil, que había tenido de esa relación tres hijos, dos de ellos fallecidos, y "que siempre se llevan de acuerdo, solamente en algunas circunstancias que se embriaga pelea con la declarante, y en algunas oportunidades ha llegado a pegarle, pero sin lesionarla, y en todas estas circunstancias, ha tomado intervención la policía, habiendo actuado correctamente, y habiéndose labrado las correspondientes actuaciones que en cada caso correspondía". Parece evidente que la declaración no es explícita de Rosa, y tampoco tiene que ver con José Domingo, sino que sirve para ratificar la supuesta eficiencia de la policía. Sigue en la misma línea, “(...) dejando aclarado que si en alguna oportunidad, vuelve a querer maltratarla le dará cuenta a la Policía, como lo ha hecho siempre".

El 29 de octubre de 1958 consta una nueva denuncia de su suegro, "Vicente Linares S/Denuncia Supuesto Estupro en perjuicio de la menor Ermelinda Linares (Acusado José Domingo Antil)". El 31 José Domingo fue detenido y, aunque continuó el 


\section{Gonzalo Pérez Álvarez - Mónica Gatica}

sumario, lo liberaron a los pocos días por orden de la instrucción. Finalmente, y sin mediar nuevas actuaciones, el 27 de noviembre se cerró el sumario preventivo.

En abril de 1963 José Domingo fue denunciado y detenido por herir con arma blanca a su hermano, Juan Antil. A fines de mayo fue liberado, después de haber estado alojado en el Depósito de Encausados, siendo condenado a una pena de ocho meses de prisión por lesiones leves en suspenso. En 1963 también se registraron actuaciones prontuariales, en torno a un incendio en su precaria vivienda.

Otra planilla de datos consta para el prontuario de 1968, donde se lo sitúa en una dirección distinta, con dos vecinos como personas que lo acompañaban habitualmente, y desempeñándose como "constructor de obras por su cuenta". Resulta de especial interés que el motivo de esta identificación fue para solicitar la radicación definitiva en el país, a 24 años de su ingreso.

Desde allí no hubo novedades, hasta el cablegrama del 3 de octubre de 1981, donde podemos leer: "Informo fecha horas 14'00 procedente Prefectura local, y a disposición Migraciones, ingresó residente ilegal JOSE DOMINGO ANTIL ALCHAO, hijo Andrés y Celinda Alchao, nacido Cautín Chile, 10-09-1925, soltero, albañil, ddo. Viamonte nr.625 ciudad, indocumentado. Solicito antecedentes radicación". Dos días después, desde el Departamento Judicial de la Policía, comunicaban que José Domingo no registraba antecedentes de radicación legal. De un día para otro fue expulsado del país, sin mediar ningún otro tipo de actuación formal, y tras casi 40 años viviendo en Argentina.

\section{Pedro José Almonacid Gallardo}

El prontuario de Pedro fue consignado como el número 181 de la sección "Expulsados", con fecha de inicio en abril de 1957. El sobre adjunto contiene cinco fotos, tres de perfil y dos de frente; también están los dos negativos, una cédula de identidad de la antigua Gobernación Militar de Comodoro Rivadavia, el formulario de la cédula provincial, y fichas dactiloscópicas de 1961, 1957 y 1972.

Era hijo de Pedro Almonacid y Luisa Gallardo, nacido en Puerto Montt, Llanquihue, el 6 de mayo de 1921. Ingresó a Argentina desde Puerto Aysén, en transporte particular durante noviembre de 1948. Se calificó su concepto, conducta y moralidad como "buena", y su aspecto social como "humilde".

Vivía en Comodoro Rivadavia, y estaba casado con una ciudadana argentina; lo "acompañaban habitualmente" dos personas, con domicilio en Barrio La Rural. En Chile era agricultor y desde que llegó en 1948 a Argentina se desempeñó como peón a jornal en distintos lugares: entre el ' 50 y el '56 fue ayudante de cañista en Obras Sanitarias de la Nación, hasta que el 17 de diciembre de 1956 se lo detuvo, acusado de lesiones. Intervino el Juez nacional de primera instancia, y allí Pedro no presentó ninguna documentación formal, pese a lo cual por entonces no sufrió la expulsión del país.

En relación a otros procesos y arrestos sufridos, Pedro tuvo detenciones por averiguación de antecedentes en marzo de 1949, y por infracciones a la resolución 


\section{Modalidades represivas contra los trabajadores chilenos en la Patagonia argentina: el caso de los obreros expulsados de Chubut}

gubernamental 960/48 en repetidas ocasiones, cumpliendo 8 días de arresto y pagando multas de manera continua. Además fue detenido en dos oportunidades por lesiones: la que reseñamos de 1956, en la cual recuperó su libertad bajo caución en enero, y otra con intervención del Juez en agosto de 1963. La víctima de lesiones en esa segunda ocasión fue Celia Mera de Almonacid, su pareja, quien denunció que Pedro la golpeó "con palos y puños”.

Con fecha 16 de mayo de 1972, la policía le devolvió formalmente las fotografías presentadas, disponiendo que no se le otorgase el documento hasta tanto no presente "Ficha de ingreso de su país de origen en el que conste el encontrarse radicado legalmente en el País". Una nueva planilla de datos señalaba que tenía domicilio en Comodoro Rivadavia desde 1948, que se rodeaba socialmente con sus compañeros de trabajo, que fue jornalero en Gas del Estado (en Pico Truncado), y que tenía familia en Chile. La identificación de ese año fue realizada porque Pedro solicitó una nueva cédula de identidad, presentando, como única acreditación formal, una exposición por pérdida de documento y un certificado de trabajo donde constaba su ingreso al país en 1948.

Otra planilla consignada a continuación, detallaba mejor su recorrido laboral y allí constaba una solicitud de renovación de cédula de identidad, fechada el 29 de abril de 1966. A continuación obra un informe del 13 de enero del mismo año, en el que se afirmaba que Pedro registraba cinco infracciones por ebriedad y desorden, abonando respectivas multas. Además se citaban otras cuatro detenciones por averiguación de antecedentes y medios de vida. Mediante radiotelegrama del 9 de febrero se informaba de su citación oficial, debido a que no estaba fehacientemente identificado por la policía.

$Y$, tal como sucede en los otros casos, sin mediar nuevas actuaciones se consigna en el prontuario una "sorpresiva" nota, donde se remitía, para antecedentes de su expulsión, a la nota 45/79 del 16 de marzo de 1979 de la URCR. Fue incorporada allí una fotocopia de ficha dactiloscópica, realizada por la policía de Santa Cruz, donde se registraba que Pedro tenía fracturados dos dedos de la mano izquierda. Allí se destacó, en manuscrito, con letra de imprenta, signos de admiración al final de la palabra, y en tinta roja, "EXPULSADO DEL PAÍS!!!".

\section{Reflexiones provisorias}

El análisis de estos expedientes de la sección "Expulsados" del Archivo de Prontuarios Policiales de Chubut, nos permite elaborar varias conclusiones, que aportarán a futuras indagaciones de mayor profundidad. El primer dato que aparece es algo que ya hemos relevado en otros trabajos (Gatica, 2013; Pérez Álvarez, 2015): la permanente vigilancia, que en muchos casos pasaba a ser represión abierta, que siempre sufrieron los trabajadores de origen chileno en la Patagonia argentina. En este trabajo logramos demostrar una de las modalidades represivas específicas, que sentenciaron a estos trabajadores de origen chileno afincados en la Patagonia argentina a llevar adelante sus vidas en una situación de permanente precariedad y 


\section{Gonzalo Pérez Álvarez - Mónica Gatica}

tensión, cual si caminasen sobre una cuerda floja, viviendo en una continua "libertad condicional".

Es insuficiente, y no refleja lo acontecido, asociar su permanencia en el país a la legalidad o la institucionalidad de la ciudadanía. La percepción de sociedad vigilada que en otras investigaciones hemos planteado, se refuerza con la documental a la que hemos accedido en este acervo: "La vida cotidiana era permanentemente espiada con operativos masivos que suponían desde el control de la documentación, los allanamientos domiciliarios sin orden judicial, un estado de requisa permanente" (Gatica, 2013: 204).

Ni conseguir un trabajo, ni obtener la radicación definitiva, ni la consecución de un documento de identidad argentino, ni siquiera construir una familia con hijos nacidos en este país, parecía asegurar que dejasen, alguna vez, de ser "ciudadanos de segunda", constantemente vigilados, observados y perseguidos. La xenofobia y el chauvinismo permean al Estado nacional en toda su extensión territorial, pero son prácticas que cuentan con una tradición más virulenta en Patagonia, donde el discurso de la soberanía en peligro, y la necesidad de "argentinizar" la región, fue parte clave de su historia. ${ }^{17}$

Así lo sostenía Osiris Villegas (1969) secretario del Consejo Nacional de Seguridad durante la dictadura de Onganía. En su escrito "Políticas y estrategias para el desarrollo y la seguridad nacional", Villegas destacaba la "peligrosidad" que según su perspectiva planteaba la presencia de migración chilena en las regiones Comahue y Patagonia (254). Para su mirada: "El elemento étnico que alimenta esta corriente migratoria trasandina no es de calidad deseable. Presenta problemas de salud, analfabetismo, mano de obra no calificada y subsecuentes repercusiones socioeconómicas" (254).

Esto generaba problemas para "la argentinización de la zona, la cual en el terreno de los hechos no está totalmente lograda" (254). Marcaba su preocupación por el peso que tenían las fiestas chilenas en la Patagonia, y el sentimiento nacional que los migrantes chilenos sostenían $(255,262)$. Además esos obreros generaban problemas gremiales, que se “...manifiestan en toda la zona de frontera y en especial en la Patagonia", ya que "los inmigrantes constituyen mano de obra barata para tareas no calificadas y sea por necesidad o por ignorancia, al no recibir lo que les acuerda la legislación laboral y convenios vigentes crean problemas" (264). ${ }^{18}$

\footnotetext{
17 Sólo dos referencias, de muchas que podrían realizarse: los señalamientos de Osvaldo Bayer (1974), en sus trabajos sobre las huelgas en la Patagonia de los años '20, y la investigación de Bohoslavsky (2009) sobre los mecanismos con los cuales grupos de derecha argentinos y chilenos concibieron la relación entre nación y territorio en Patagonia.

${ }^{18}$ Es pertinente revisar las movilidades para categorizar y conceptualizar sus componentes causales, ya que hay dificultades analíticas en los procesos migratorios en los que confluyen situaciones combinadas en las que no es fácil -metodológicamente hablando- desentrañar los pesos relativos y las formas en que interactúan y se condicionan. Otro punto importante a señalar es que toda experiencia migratoria, tiene que ver con proyectos de Estado y prácticas gubernamentales (Casillas, 2015). Así enfatizamos la necesidad de pensar su carácter multidimensional: por un lado, las personas se mueven como consecuencia de unas circunstancias, donde el Estado tiene una alta cuota de responsabilidad, pero por otro también es fundamental pensar en que las y los migrantes hacen una lectura de su propia realidad vivida y de las opciones y recursos con los que cuentan y, a partir
} 


\section{Modalidades represivas contra los trabajadores chilenos en la Patagonia argentina: el caso de los obreros expulsados de Chubut}

Es necesario entrecruzar estas historias de vidas obreras con la periodización político-estatal de los conflictos territoriales y/o limítrofes entre Argentina y Chile. El año 1978 fue un parte aguas y, como vimos, allí se ubicaron la mayoría de las detenciones y expulsiones de estos trabajadores de origen chileno en la Patagonia argentina; de hecho es en esa coyuntura cuando se crea la sección "Expulsados". Un acontecimiento político, que derivó en la explícita tensión militar entre dos dictaduras, generó una trágica ruptura en las vidas de estos obreros, parte de cuyas consecuencias podemos entrever en base a estos documentos.

La intersección del funcionamiento represivo con el género no parece tan clara. La escasa presencia de mujeres en el listado de "Expulsados" transcripto, y el hecho de no haber encontrado ningún prontuario de una mujer expulsada, puede referir a que la perspectiva machista de los represores los hacía considerar a la mujer como una amenaza más débil, especialmente si se la separaba del "hombre".

Esto puede haber funcionado a modo de protección para muchas obreras de origen chileno, algunas de ellas con profusas historias militantes. Pero a la vez daba cuenta de una opresión más profunda y permanente, de la cual esas mujeres eran víctimas cotidianas, dentro y fuera del hogar, sufriendo la violencia del Estado y de los hombres con quienes compartían su vida. Lo observado en los prontuarios de José Domingo y Pedro, brindan indicios en tal sentido. La invisibilización del rol activo de la mujer, que parecía protegerla de la persecución estatal, era la clave para ocultar su constante opresión.

Claramente llevamos adelante un análisis de clase de estos indicios, que integra necesariamente el tamiz de género. Creemos demostrado que es su origen de clase la clave explicativa para comprender las razones de la persecución que sufren por parte del Estado; la clave de la "nacionalidad" estaba intervenida y atravesada por su rol económico y social. Se los persigue más por obreros que por chilenos: la nacionalidad da una buena "excusa" para amedrentar y disciplinar al conjunto de la clase obrera. Muchos testimonios de trabajadores muestran que la desaparición de un chileno compañero de labor, impactaba en el conjunto del colectivo obrero de la empresa donde éste se desempeñaba (Pérez Álvarez, 2015) ${ }^{19}$.

No hemos registrado chilenos expulsados que fuesen propietarios o profesionales, o tuviesen algún capital. Como vimos, son todos obreros de las tareas más duras: jornaleros de la actividad petrolera, ladrilleros, peones rurales, albañiles. Ellos eran necesarios para los momentos de expansión, y para sortear la escasez de fuerza de

de esto, deciden (reconociendo diferentes niveles en cuanto a la toma de decisiones y el papel de terceros en ellas). Por tanto, nos parece fundamental reconocerles su capacidad de agencia, de pensar en formas de transformar su realidad o en la construcción de proyectos de futuro a partir de la migración como una estrategia (Artola, 2005; Bjerg \& Otero, 1995; Coraza \& Gatica, 2018).

${ }^{19}$ Sólo por citar uno de tantos ejemplos posibles, René Pérez nos narraba que “...siempre estaba el rumor de la noticia no confirmada del terror, viste. Estaba el rumor de que a fulano en una fábrica lo echaron con toda su familia, lo dejaron en la frontera y los pacos lo cagaron a palos". Entrevista realizada el 4 de julio de 2009 por Gonzalo Pérez Álvarez. René es chileno, y en su testimonio el término "pacos" refiere a la policía militarizada de Chile. 


\section{Gonzalo Pérez Álvarez - Mónica Gatica}

trabajo, pero aparecían como amenazantes cuando se modificaba la coyuntura internacional, o ante una crisis económica que aumentase el desempleo.

Los estudios de estas características aportan a develar las dinámicas políticas y sociales que la violencia estatal ha supuesto para ciertos colectivos. Se trasciende una temporalidad limitada al período de dictadura, ya que algunos de los casos evidencian que las arbitrariedades se proyectan hasta los años de democracia.

\section{Coda final: sobre el pasado que es constructor del futuro}

Creemos que se queda corta aquella referencia historiográfica acerca de que investigamos el pasado desde las preguntas del presente (Fontana, 1982). Entendemos que nos acercamos a esos procesos ocurridos en el pasado desde las preguntas del futuro; del futuro que soñamos construir, o del que aceptamos como inevitable cuando simplemente nos adaptamos a lo que nos impone el poder (Pérez Álvarez, 2018).

Desde el siglo XXI parece vivirse un mundo sin utopías, en el cual el pasado no es visto como un tiempo de revoluciones sino de violencias. Los testigos hablan por las víctimas, y la memoria colectiva se transforma en un duelo inagotable. Pretendemos aportar a su restitución, es decir a hacer visibles sus experiencias y trayectorias, trabajando, al decir de los culturalistas ingleses, en una "historia desde abajo".

Cuando como historiadores decidimos preguntarnos sobre estos obreros chilenos "expulsados" de la Patagonia argentina por un Estado represivo, lo hicimos preocupados por el futuro que parece asomarse, volviendo a mostrar los conocidos nubarrones de xenofobia y chauvinismo. Al transitar un tiempo sin utopías comienza a mirarse inevitablemente hacia atrás, y recurrentemente se alude a las víctimas; optamos por restituirlos en tanto sujetos, recuperando sus trayectorias laborales, sus vínculos, su experiencia. Intentamos superar el problema que destaca Traverso, cuando alerta que "la rememoración de las víctimas parece incapaz de coexistir con el recuerdo de sus esperanzas, sus luchas, sus victorias y sus derrotas" (2018: 39).

La idea de ese pasado que irrumpe en el presente como clave para construir otro futuro, y que en ocasiones puede sonar a una expresión abstracta, nos arrasó con su literalidad al momento de estar escribiendo este artículo. Cuando procedíamos a plasmar las ideas y resultados en el papel, esas prácticas represivas, que ingenuamente pueden parecer del "pasado", hasta de un Estado un tanto arcaico en sus métodos, se nos actualizó de manera tenebrosa. El gobierno provincial de Chubut ${ }^{20}$ decretó en febrero de 2019: "la expulsión y prohibición de ingreso a la Provincia de Chubut de ciudadanos extranjeros que hubieran sido condenados o se

20 El gobierno provincial es dirigido por “Chubut Somos Todos”, partido político de carácter provincial fundado por Mario Das Neves tras su ruptura con el kirchnerismo. Luego de la muerte de Das Neves (en octubre de 2017), su vicegobernador Mariano Arcioni continuo su mandato, siendo reelecto en las elecciones provinciales desarrolladas en junio del 2019. 


\section{Modalidades represivas contra los trabajadores chilenos en la Patagonia argentina: el caso de los obreros expulsados de Chubut}

encuentren cumpliendo condena, que reúnan antecedentes penales o condena no firme por delitos cometidos en la República Argentina o en el extranjero".21

El decreto choca con las más básicas garantías democráticas. ${ }^{22}$ De todas maneras, y como lo vimos en los prontuarios, que un procedimiento sea impropio o hasta ilegal, no detiene las prácticas represivas de la maquinaria estatal. Esa matriz chauvinista y represiva del Estado argentino en Patagonia, que creíamos debíamos demostrar, se hizo palmariamente evidente.

También se hace indudable la necesidad de recrear una historia que recupere la noción de que su tarea clave es la de construir conocimiento que en manos de los sujetos colectivos concretos se transfigure en fuerza material para combatir las injusticias del presente y edificar un futuro igualitario. Recuperamos la clásica noción de la historia como arma que combate hacia el futuro (Moreno Fraginals, 1983).

Pensamos con Benjamín que recordar es rescatar, pero también implica cambiar el presente. Tenemos que hacer renacer las esperanzas de los vencidos, dar nueva vida a las esperanzas incumplidas: "Escribir la historia no es un trabajo de reconstrucción abstracta, sino la dimensión intelectual de una transformación política del presente. El conocimiento histórico es un acto revolucionario que no puede confundirse con la mera erudición" (Traverso, 2018: 381).

¿Cómo construir las preguntas que necesitamos? Fundamentalmente desde las historias de los vencidos (Cerio, 2014; Benjamin, 2007), de los perseguidos, de los silenciados. Sin romanticismos, ni falsos embellecimientos: eran hombres de carne y hueso, que reproducían muchas de las peores prácticas de la sociedad que habitaban. Aun así en estos prontuarios encontramos indicios de esos sueños rotos, de esas familias destrozadas. Fueron colectivos enteros que sufrieron estas injusticias... Esperamos que conocer y divulgarlas pueda iluminar el presente, para impedir un nuevo futuro de tinieblas. Trabajamos para que nuestra investigación aporte, al menos, algunas claves para alumbrar ese camino.

\section{Bibliografía}

Águila, G. (2018). La represión en la historia reciente como objeto de estudio: problemas, novedades y derivas historiográficas. En Águila, G.; Luciani, L.; Seminara, L. \& Viano, C. (comps.). La historia reciente en Argentina. Balances de una historiografía pionera en América Latina. Buenos Aires: Imago Mundi. pp. 55-72.

\footnotetext{
21 https://www.elchubut.com.ar/nota/2019-2-6-14-29-0-arcioni-firmo-un-decreto-para-echar-dechubut-a-extranjeros-delincuentes/galeria.

${ }^{22}$ La misma ministra de seguridad del gobierno nacional, Patricia Bullrich, llamó la atención sobre los problemas legales que su implementación podría acarrear, avalando la iniciativa en términos políticos pero cuestionando la forma de implementación: https://www.elpatagonico.com/bullrichle-pedira-arcioni-que-marcha-atras-el-decreto-los-extranjeros-que-delinquen-n5015193.
} 


\section{Gonzalo Pérez Álvarez - Mónica Gatica}

Arendt, H. (1999). Eichmann en Jerusalén. Barcelona: Lumen.

Artola, J. (2005). "Debate actual sobre migración y seguridad", en Migración y Desarrollo, no 5. UAM: Zacatecas. pp. 136-1.

Bandieri, S. (2005). Historia de la Patagonia. Buenos Aires: Editorial Sudamericana. Bandieri, S. (2011. comp.). La historia económica y los procesos de independencia en la América hispana. Buenos Aires: Prometeo Libros.

Barros, S. \& Carrizo, G. (2012). La política en otro lado Los desafíos de analizar los orígenes del sistema político chubutense. En Ruffini, M. (coord.) Dossier: De territorios a provincias. Actores, partidos y estrategias en las nuevas provincias argentinas (1951-1962). Recuperado de http://historiapolitica.com/datos/biblioteca/territoriosaprovincias barrosycarriz o.pdf.

Bayer, 0. (1974). Los vengadores de la Patagonia trágica. Tomo 1. Buenos Aires: Editorial Galerna.

Benjamin, W. (2007). Conceptos de filosofía de la historia. Buenos Aires: Caronte. Bjerg, M. \& Otero, H. (1995; comps). Inmigración y Redes Sociales en la Argentina Moderna. CEMLA-IEHS: Buenos Aires.

Bohoslavsky, E. (2007). "Gobernar es vigilar. Miradas nacionalistas sobre la Patagonia (1934-43)", en revista Ciclos en la historia, la economía y la sociedad, año XVII, vol. XVI, n 31/32. Buenos Aires: Fundación de Investigaciones Históricas, Económicas y Sociales. pp. 3-24.

Bohoslavsky, E. (2009). El complot patagónico. Nación, conspiracionismo y violencia en el sur de Argentina y Chile (siglos XIX y XX). Buenos Aires: Prometeo Libros.

Caimari, L. (2017). La vida en el archivo. Goces, tedios y desvíos en el oficio de la historia. Buenos Aires: Siglo XXI.

Casillas, R. (2015). La migración de algunos y la inseguridad de todos. Análisis y recomendaciones para pasar de la ficción al trato humanitario. Instituto Tecnológico Autónomo de México: México.

Cerio, D. (2014). Una cita revolucionaria: Walter Benjamin y la historia de los vencidos. En Viano, C. (edit.) Miradas sobre la Historia. Fragmentos de un recorrido. Rosario: Prohistoria. pp. 15-34. 


\section{Modalidades represivas contra los trabajadores chilenos en la Patagonia argentina: el caso de los obreros expulsados de Chubut}

Coraza, E. \& Gatica, M. (2018). "Los exilios políticos y la dimensión comparada: contribuciones a un campo en construcción", en Revista de Ciencias Sociales y Humanidades, vol. 27, no 53. pp. 1-21.

Farge, A. (1991). La atracción del archivo. Valencia: Alfonso el Magnánimo.

Fontana, J. (1982). Historia. Análisis del pasado y proyecto social, Barcelona: Crítica.

Gatica, M. (1998). Trelew, ¿un polo de desarrollo y modernización?. En Actas IV Jornadas de Historia. Caleta Olivia: UNPA.

Gatica, M. (2011). Un archivo de la represión en Rawson. En revista Anuario de la Escuela de Historia no22. Rosario: UNR. pp. 157-182.

Gatica, M. (2013). ¿Exilio, migración, destierro? Trabajadores chilenos en el noreste de Chubut (1973-2010). Buenos Aires: Prometeo Libros.

Geertz, C. (1983). La interpretación de las culturas. Barcelona: Gedisa.

Gilly, A., Subcomandante Marcos \& Ginzburg, C. (1995). Discusión sobre la historia, México: Taurus.

Ginzburg, C. (1998). El queso y los gusanos. El cosmos según un molinero del siglo XVI. México: Océano.

Ginzburg, C. (2013). Mitos, indicios y emblemas. Morfología e Historia. Buenos Aires: Prometeo Libros.

Gramsci, A. (1997). Notas sobre Maquiavelo, sobre la política y sobre el Estado moderno. Buenos Aires: Nueva Visión.

Moreno Fraginals, M. (1983). La historia como arma y otros estudios sobre esclavos, ingenios y plantaciones. Barcelona: Crítica.

Nazar, M. \& Linares, A. (2007). "El hilo de Ariadna", en Políticas de la Memoria, Anuario de Investigación del CeDInCI, nº6-7. Buenos Aires: CeDInCI. pp. 212-218.

Pasolini, R. (2017). Reseña "Lila Caimari, 2017. La vida en el archivo. Goces, tedios y desvíos en el oficio de la historia. Buenos Aires: Siglo XXI. 144 p. En Anuario IEHS 32 (2), pp. 243-245.

Payeras, M. \& Guillén, R. S. (2003). Las enseñanzas de la montaña 1972, 1984. En Vos, Jan de (comp.). Viajes al desierto de la soledad. Un retrato hablado de la Selva Lacandona. México: CIESAS. pp. 317-332. 


\section{Gonzalo Pérez Álvarez - Mónica Gatica}

Pérez Álvarez, G. (2013). Patagonia, conflictividad social y neoliberalismo 1990-2005. Buenos Aires: Imago Mundi.

Pérez Álvarez G. (2015). El aporte de la migración chilena a la formación de una nueva clase obrera en el noreste de Chubut: 1956-1989. En Cuadernos de Historia, $\mathrm{n}^{\circ}$ 43. Santiago de Chile: Universidad de Chile. pp. 59-81.

Pérez Álvarez, G. (2016). Amazônia Brasileira e Patagônia Argentina: planos de desenvolvimento e soberania nacional. En Estudos Avançados vol.30 n 88. San Pablo: USP. pp. 117-138.

Pérez Álvarez, G. (2018). Por una Historia de (hacia) el futuro. En revista Historia Actual Online $n^{\circ}$ 45. Cádiz: Universidad de Cádiz. pp. 157-169. Recuperado de: http://historia-

actual.org/Publicaciones/index.php/haol/article/view/1461/1188.

Ricoeur, P. (1999). Historia y narratividad. Barcelona: Paidós.

Ruffini, M. (2012). “Un orden institucionalizara las nuevas Provincias Argentinas en Tiempos de la "Revolución Libertadora". Democracia y ciudadanía en los debates de la Convención Constituyente de Río Negro (1957)”, en Revista Historia Caribe, Volumen VII, pp. 77-100.

Sirimarco, M. (2010). Estudiar la policía. La mirada de las ciencias sociales sobre la institución policial. Buenos Aires: Teseo.

Sub Comandante Marcos (1996). Carta a Adolfo Gilly a propósito de Carlo Guinzburg, Debate. En Razón y Revolución nํ2, reedición electrónica.

Traverso, E. (2018). Melancolía de izquierda. Marxismo, historia y memoria. México: Fondo de Cultura Económica.

Villegas, O. (1969). Políticas y estrategias para el desarrollo y la seguridad nacional. Buenos Aires: Círculo Militar.

Recibido: 30/08/2019

Evaluado: 01/10/2019

Versión Final: 02/11/2019 